\title{
Variability in dynamic daylight simulation in clear sky conditions according to selected weather file: Satellite data and land-based station data
}

\author{
JM Monteoliva PhD, A Villalba PhD and AE Pattini PhD \\ Laboratorio de Ambiente Humano y Vivienda, Instituto de Ciencias \\ Humanas, Sociales y Ambientales, Consejo Nacional de Investigaciones \\ Científicas y Técnicas, Mendoza, Argentina
}

Received 2 September 2015; Revised 10 November 2015; Accepted 23 November 2015

\begin{abstract}
While the use of satellite weather files is a possibility in regions without terrestrial stations, it is necessary to consider their impact on daylight simulations. This paper aims to verify the variability of dynamic daylight simulation results according to the weather file used. This study compares the results of daylight simulations in learning spaces using different weather files (land-based station data and satellite data). This work is divided into three main stages: comparative analysis of climatic databases; comparative analysis of annual outside horizontal illuminance; analysis of dynamic daylight performance metrics. Annual calculated dynamic daylight metric indicates variations of up to $13 \%$ under the different weather files analysed. This is a relevant topic since the accurate prediction of daylight levels for indoor environments guides daylighting design.
\end{abstract}

\section{Introduction}

An accurate estimation of the quantity of incoming light is necessary for an evaluation of the visual capacity and energy efficiency provided by daylight. ${ }^{1}$ The most adequate stage for determining the behaviour of indoor daylighting takes place during the design phase, when the location, configuration, window placement and shading devices are formulated. These decisions affect the quantity and quality of lighting, costs, views, solar gain and energy use. Furthermore, daylight enhances the performance and productivity of

Address for correspondence: JM Monteoliva, Laboratorio de Ambiente Humano y Vivienda - INCIHUSA CONICET, Av. Ruiz Leal S/N Parque General San Martín - Ciudad de Mendoza, Mendoza, Argentina.

E-mail: jmonteoliva@mendoza-conicet.gob.ar the inhabitants, affects mood and plays a fundamental role in the regulation of the human circadian system. ${ }^{2-6}$

One of the problems of daylight design is the correct determination of its availability during the year and its great variability over time. The need to predict indoor daylight variations according to different factors (building orientation, weather conditions, time of day, etc.) has led to the development of multiple advances in the numerical analysis of daylight. Some of the main developments within this topic are: Predictive calculations based on the International Commission on Illumination (CIE) sky models (CIE overcast, CIE clear, CIE sunny) - static simulation ${ }^{7,8}$ climate and sky luminance distribution data dynamic simulation. ${ }^{9,10}$ Dynamic simulations consist of different computational steps. 
The first is the definition of the external luminous conditions that characterize the location and correspond to each hour of the year. Software used for dynamic daylight simulations can calculate these luminous conditions by using the direct and diffuse irradiance (IDif) values contained in weather data files in conjunction with sky luminance distribution models. ${ }^{11}$

On a sunny day, the main light source in the sky comes directly from the sun. But, as direct sunlight disperses in the atmosphere, the sky itself becomes a source of visible light, i.e. we divide the sunlight into direct and diffuse components. For clear or sunny skies, as is the usual case in Mendoza and many other cities of the world, the sky luminance distribution model can create accurate predictive simulation results. Also, in contrast to the CIE sky model used in static simulations, the Pérez sky model (radiance) can predict annual lighting conditions for an area based on the climate data of the studied region. Climate data files contain information about date, time and location as well as direct and IDif values, which, in combination with the Pérez model, allow for the calculation of the sky luminance distribution. ${ }^{12}$

Nowadays, tools used for predictive simulations can accurately model indoor daylight behaviour, reducing the demand and use of scale models. However, these models require an accurate description and characterization of the light source - global and direct irradiance (ID)..$^{9}$ Thus, the availability of global solar radiation distribution data is crucial. Weather data files, like the ones offered by the Illuminating Engineering Society (IES), thermal analysis simulation software and EnergyPlus, are employed in order to characterize the annual weather of a location under study with higher precision. Climate files may be presented in different formats: Test reference year, typical meteorological year, example weather year; however, all climate files contain typical annual weather patterns on an hourly basis $(8760 \mathrm{~h} /$ year). Still, most scientists and project designers studying daylight in clear sky regions do not have this data for their location from weather stations. ${ }^{11}$ An alternative to these methods of interpolation-extrapolation of data from weather stations is the use of satellite information. This involves the use of weather data offered by commercial software (e.g. Meteornom) or companies involved in the development of satellite weather databases (e.g. weather analytics). The accuracy of satellite values depends on the resolution of the image. Thus, satellite solar irradiation values associated with large pixels involve considerable climatic and topographic variability, and these can generate high levels of uncertainty about the information provided. ${ }^{13}$

This paper aims to verify variations concerning daylight simulation results and the type of weather file employed. This study compares the results of daylight simulations in a classroom obtained with different weather data files - satellite data and land-based station data - for Mendoza (Argentina). This is a relevant topic since the accurate prediction of indoor environmental daylight levels guides' daylighting design and its integration with electric light systems; therefore, different simulated daylight indicators and illuminance values may have a significant impact on the prediction of energy consumptions caused by different design options. ${ }^{14}$ Iversen et al. ${ }^{15}$ investigated the effects of using three different weather data files (design reference year, International Weather Years for Energy Calculation [IWEC] and Meteonorm) on the results of dynamic daylight simulations carried out for a south-oriented office located in Copenhagen. They analysed the outcomes in terms of lighting dependencies and found differences of up to $2 \%$. Bellia et al. ${ }^{14}$ compared results obtained by performing dynamic daylight simulations of a simple north-oriented office located in five 
European cities. They found that the use of IWEC, Meteonorm and Satel-Light weather data files produced similar results in terms of dynamic daylight performance metrics, whereas significant differences were obtained for annual and monthly light exposures.

\section{Methodology}

First, this paper presents a comparative analysis of direct and IDif statistics of three different climatic bases: Satellite data (ARG_MzaMN6 and ARG_MzaAP) and land-based station data (AR̄G_MzaCCT). Subsequently, a comparison is made of the annual exterior horizontal illuminance according to ARG_MzaMN6 and ARG MzaCCT. In this part of the methodology, satellite-based ARG_MzaAP is dismissed because no differences with ARG_MzaMN6 were found. A deeper analysis of the selected satellite weather data files can be found in previous studies. ${ }^{16}$ The conversion of radiation units $\left(\mathrm{W} / \mathrm{m}^{2}\right)$ to photometric units $(\mathrm{lx})$ is carried out using the daylight coefficient. ${ }^{17,18}$ The annual availability of daylight (lumen per square metre [lux]) is quantified through dynamic daylight simulations with an unobstructed exterior horizontal illuminance (Eh) sensor, located at a height of $0.80 \mathrm{~m}$. Annual and seasonal results are analysed in three ranges of illuminance: $10,000 \mathrm{~lx}, 10,000$ $100,0001 \mathrm{x}$ and $100,0001 \mathrm{x}$, with the SeasonSIM $\odot$ v.1.0 tool. ${ }^{18}$ The importance of the seasonal analysis for clear sky conditions and the specific case of the region under study lies in the significant differences of global illuminance availability between summer and winter periods $(60,000 \mathrm{~lx})$.

In addition, this investigation compares the variability of annual and seasonal dynamic daylight simulation results (adjustable useful daylight illuminance (aUDI) and spatial daylight autonomy (sDA)) according to the selected climate files. This section aims to further analyse the variability of the availability of daylight within a space according to ARG_MzaMN6 and ARG_MzaCCT sky conditions. Two typical classrooms of a regional school were used to perform the simulations in indoor spaces. Each has different window orientations: north-south (NS) and east-west (EW).

The study was conducted in the City of Mendoza, Argentina. The metropolitan area of Mendoza is located in a semi-arid region of western Argentina. The sky is predominantly sunny, $83 \%$ of the year, or partly cloudy with presence of sun (Argentine National Weather Service for the period 1981-1990). The average annual number of hours of sunlight is $2850 \mathrm{~h}$. Mean maximum global illuminance values are 90,000 $\mathrm{lx}$ in summer and 30,000 lx in winter. $^{20}$ The clear sky - dynamic sky condition - of this region is particularly interesting for the study of the daylight performance of buildings through dynamic daylight simulation.

\subsection{Weather data files}

Simulations were performed using three different weather data files: ARG_MzaMN6 and ARG_MzaAP (satellite data Meteonorm) and ARG_MzaCCT (landbased station data - INC $\bar{C}$ IHUSA station). As mentioned in prior studies, ${ }^{16,21}$ there are currently no weather data files for Mendoza City in predictive software such as DAYSIM or EnergyPlus. Therefore, it was necessary to generate a weather data file based on logs from the daylight station at INCIHUSA CCT Mendoza (ARG_MzaCCT) in order to compare with the satellite weather data provided by Meteonorm (ARG_MzaMN6 and ARG_MzaAP). Minute to minute data were supplied by the daylight measurement station of the Institute of Social, Human and Environmental Sciences (INCIHUSA) Laboratory of Human Environment and Housing, located at the Mendoza Science and Technology Center ( $\left.32^{\circ} 53^{\prime} \mathrm{S}-68^{\circ} 51^{\prime} \mathrm{W}\right)$ (Figure 1). 


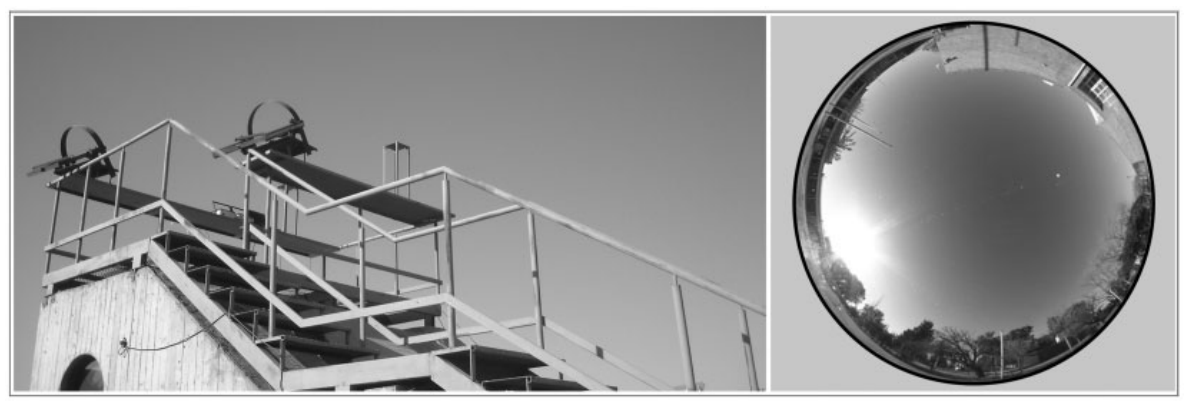

Figure 1. Daylight measurement station of the Institute of Social, Human and Environmental Sciences (INCIHUSA).

This station belongs to the IDMP network and records the values of global horizontal radiation, diffuse horizontal radiation, global horizontal illuminance and diffuse horizontal illuminance. These data are taken automatically by a micro-controller MC68H11 through four sensors (horizontal illuminance and irradiance, global and diffuse, respectively) and are checked in accordance with the quality controls established by $\mathrm{CIE}^{22}$ for the worldwide stations network. The climate file generated, ARG_MzaCCT, provides validated, reliable, global horizontal and IDif data for Mendoza City.

On the other hand, Meteonorm is a product developed by METEOTEST, with experience in the field of meteorological databases for energy applications. The database is made up of data from 8325 weather stations worldwide along with five geostationary satellites with global coverage. In areas with few meteorological stations, the parameters measured (radiation, temperature, humidity, rain, precipitation, precipitation days, wind speed and direction, sun hours, global UVA) are based on satellite data. The weather data obtained for the city of Mendoza were ARG_MzaMN6 (latitude -32.70; longitude 68.00; Time zone 60, site elevation $780 \mathrm{msm}$ ) and ARG_MzaAP (latitude -32.83; longitude 68.78; time zone 60; site elevation 704 $\mathrm{msm})$. The extensions for the weather files provided by the software are: weather file
EnergyPlus (*.epw), data synthesis report (*.stat) and daily design conditions (*.ddy), information about aspects and limitations of Meteonorm (*.info) and details of the statistics process (including errors) (*.audit).

\subsection{Daylight simulations}

Daylight simulations were performed with Daysim (v3.1 e beta). Daysim is a radiancebased tool developed by the National Research Council of Canada and the Fraunhofer Institute for Solar Energy Systems, Germany. This software employs optimization methods for the calculation of luminance and luminance-distribution under different annual weather conditions under the Perez sky model. Likewise, it provides different metrics for predictive daylight annual analysis such as daylight autonomy (DA), ${ }^{23}$ continuous daylight autonomy ${ }^{18}$ and useful daylight index (UDI). ${ }^{24,25}$

The simulation parameters used in Daysim correspond to a simple scene of translucent, transparent and opaque elements without a complex daylighting system ${ }^{10}(\mathrm{ab}) 5$; (ad) 1000; (as) 100; (aa) 0.1; (ar) 300; (dt) 0; (ds) 0 . A target illuminance of $500 \mathrm{~lx}$ on the workplane was considered (IRAM AADL J20 04 and EN 12464-1 Light and Lighting - Lighting of Work Places - Part I: Indoor Work Places, 2011). In order to analyse the luminous behaviour inside the space, two dynamic daylighting metrics were selected: aUDI ${ }^{26}$ and sDA. The selection 
of these metrics enables, on the one hand, the identification of the percentage of occurrence of illuminance within a given range; and, on the other, the detection of sufficient daylight.

\subsection{1. aUDI}

This metric is based on the useful daylight illuminance (UDI) ${ }^{24,25}$ and its limitation in the adjustment of the lower and higher limits of the illuminance range. In this way, the aUDI percentage represents illuminance occurrence (as a point or on a grid) within a useful range throughout the year. The importance of this metric, with respect to UDI, is the possibility of adjusting the range considered 'useful', according to the specific requirements of the assessments. In this case study, based on existing national standards IRAM AADL J2004, the upper and lower limits selected in the useful range are 500 lx and $25001 \mathrm{x}$, respectively $\left(\mathrm{aUDI}_{500-25001 \mathrm{x}}\right)$. In a complementary way, lower $(\mathrm{aUDI}<5001 \mathrm{x})$ or higher $\left(\mathrm{aUDI}_{>2500 \mathrm{l}}\right)$ than the useful range values are assessed. In order to deepen the study, the percentage of space with an aUDI $500-2500 \mathrm{~lx}$ larger than $50 \%$ is analysed. As proposed by the IES LM-82-12 $2^{27}$ with indicators sDA and annual sunlight exposure, this analysis gives a clear vision of the area percentage that meets illuminance values, within the established range for specified fraction of the operating hours per year (50\% of the hours).

\subsection{2. $s D A$}

This metric describes the adequacy of ambient daylight levels within interior environments, annually. It is defined through a percentage of an area of analysis that meets minimum daylight illuminances for a specified fraction of the hours of the year that the space is occupied. The illuminance level and time fraction are included as subscripts, as in $\mathrm{sDA}_{500,50 \%}$. The $\mathrm{sDA}$ value is expressed as a percentage of area. ${ }^{27}$ As proposed by the IES LM-82-12 $2^{27}$ with the indicator $\mathrm{sDA}$, this analysis gives a clear vision of the area percentage that meets illuminance requirements within the established range for a specified fraction of the operating hours per year $(50 \%$ of the hours).

Two sets of simulation results were obtained, corresponding to each space, according to the two analysed weather data files (ARG_MzaMN6, ARG_MzaCCT). The study is based, first, on the comparative annual analysis of the results obtained relative to outside horizontal illuminance; and, second, on the particular case of aUDI $\left(\mathrm{aUDI}_{<500 \mathrm{~lx}} ; \mathrm{aUDI}_{500-2500 \mathrm{~lx}} ; \mathrm{aUDI}_{>2500 \mathrm{~lx}}\right.$ ); aUDI $_{500-25001 \mathrm{x}, 50 \%}$ and $\mathrm{sDA}_{500}$ lux, $50 \%$ at different times of the year (annual and seasonal), which are analysed within the hours of available sunlight (acronym in Spanish, HsDRS) (Table 1). The seasonal analysis is carried out with SeasonSIM(C) v.1.0, ${ }^{19}$ a post-processing statistical tool for dynamic daylight analysis. The main objective is to broaden the dynamic analysis of useful daylight ranges while preserving a rigorous ray tracing methodology used in the simulation tools (radiance). The main features are: (i) to provide adjustable ranges for the analysis of daylight through the aUDI and (ii) to study, according to the season, the main daylight dynamic metrics. With the

Table 1. Criteria used for the categorization of seasons.

\begin{tabular}{llll}
\hline Period & Central Value & Range & HsDRS \\
\hline 1 & Summer Solstice (21 December) & 6 November to 5 February & 14 hs \\
2 & Autumn Equinox (21 March) & 6 February to 5 May & 12 hs \\
3 & Spring Equinox (21 September) & 6 August to 5 November & 8 May to 5 August \\
\hline
\end{tabular}


application SeasonSIM, annual and seasonal aUDI, aUDI ${ }_{500-25001 \times}, 50 \%$ and $\mathrm{sDA}_{500,50 \%}$ are analysed.

\subsubsection{Space configuration}

The institution selected for simulation is the School of the Republic of Chile (no. 1256) (Figure 2). This educational building is located $3 \mathrm{~km}$ from the capital of the province of Mendoza ( $32^{\circ} 52^{\prime} 49^{\prime \prime} \mathrm{S}, 68^{\circ} 52^{\prime} 45^{\prime \prime} \mathrm{W}-853$ $\mathrm{msm})$ in an area of medium building density. Within the institution, two classrooms, one with EW window orientation (A2) and one with NS window orientation (A3), were selected (Figure 3).
Classroom A3 and classroom A2 have glazed areas, at eye level, which cover $90 \%$ of the length of the façade. These are located on the south façade in A3 and on the east façade in A2. In classroom A3, north façade windows are located at the top of the wall and are partially obstructed by outside trees (Cupressus sempervirens, evergreen tree with a pyramid shape). In classroom A2, the west facade windows are located at the top of the wall. The analysis grid used in both cases to perform the simulations is $7.95 \mathrm{~m} \times 6.00 \mathrm{~m}$ $\left(47.7 \mathrm{~m}^{2}\right)$ and was located at a height of $0.80 \mathrm{~m}$ from the floor and included 12 sensors. It is noteworthy that the glassed surfaces do not have shading devices. Surface reflectances
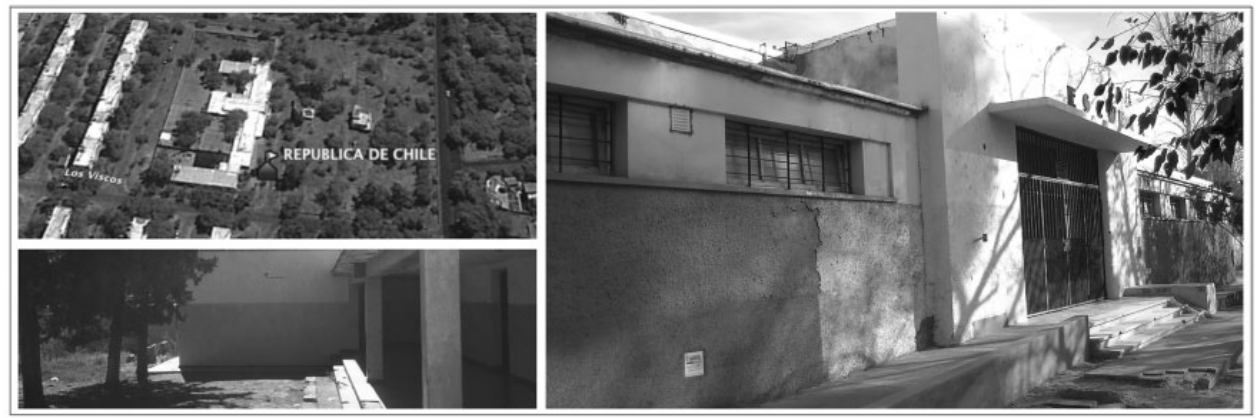

Figure 2. Republic of Chile $\mathrm{N}^{\circ} 1256$ primary school.

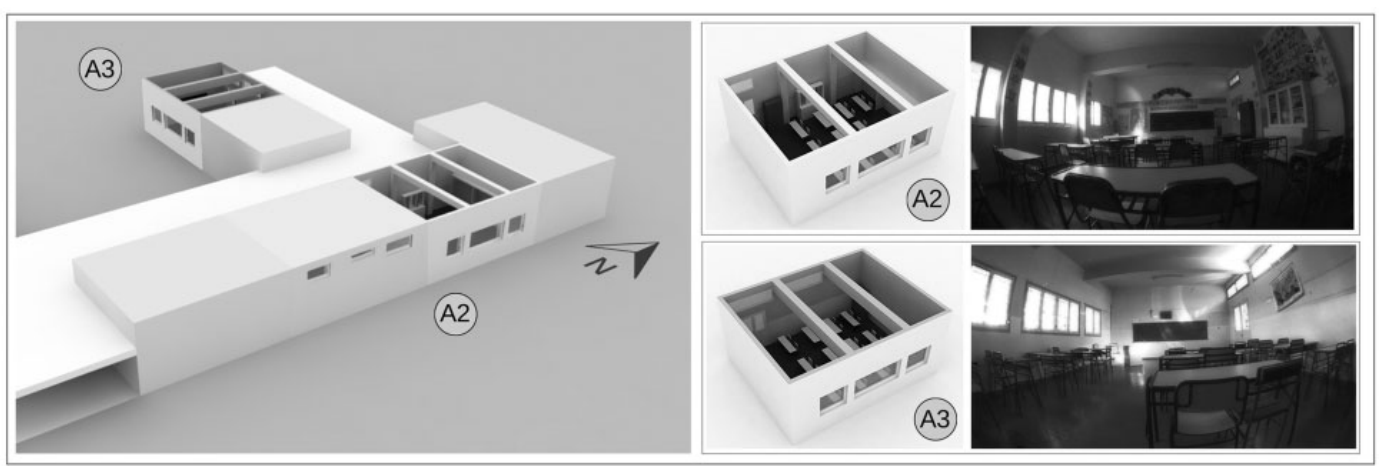

Figure 3. Classrooms for study (A2 and A3) - Republic of Chile N ${ }^{\circ} 1256$ Primary School. 
are the following: external walls $35 \%$, internal walls $60 \%$; ceiling $80 \%$; floor $30 \%$; outside ground $20 \%$. Windows have a single clear glass pane: visible transmittance 0.91 , visible front reflectance 0.082 and visible back reflectance 0.082 (Pilkington North America).

\section{Results}

\subsection{ID and IDif}

The statistics from the three analysed databases - ARG_MzaMN6, ARG_MzaAP and ARG_MzaCC̄T - for values of annual ID (MN6 ID, AP ID and CCT ID) and IDif (MN6_IDif, AP_IDif and CCT_IDif) over $1 \mathrm{~W} / \mathrm{m}^{2}$ are presented in Table 2 . The time period considered in the analysis was confined to those hours that solar radiation is available as a resource for lighting.

The analysis focuses on the parameters of mean (X), standard deviation (DS) and asymmetry (A) obtained for ID and IDif. First, it can be observed that the major difference between arithmetic means $(\Delta \mathrm{X})$ of ID was $83.4 \mathrm{~W} / \mathrm{m}^{2}$, among the CCT_ID (X= $\left.598.3 \mathrm{~W} / \mathrm{m}^{2}\right)$ and MN6_ID $\left(\mathrm{X}=5 \overline{14} .9 \mathrm{~W} / \mathrm{m}^{2}\right)$; whereas for IDif the highest discrepancy was of $26 \mathrm{~W} / \mathrm{m}^{2}$ between CCT_IDif $\left(\mathrm{X}=117.7 \mathrm{~W} / \mathrm{m}^{2}\right)$ and AP_IDif $\left(\Delta X=1 \overline{4} 3.7 \mathrm{~W} / \mathrm{m}^{2}\right)$. Regarding the $\mathrm{DS}$, the highest difference in ID was of $9.5 \mathrm{~W} / \mathrm{m}^{2}$ among CCT_ID $(\mathrm{DS}=337.2)$ and
MN6_ID (DS=327.7); whereas for IDif, it reachèd $30.3 \mathrm{~W} / \mathrm{m}^{2}$ between CCT_IDif $(\mathrm{DS}=87)$ and MN6_IDif $(\mathrm{DS}=117.2)$. This highlights a greater dispersion of ID data with respect to IDif; however, the greatest difference was noted for the IDif values. Asymmetries (A) show a negative asymmetric tendency for CCT_ID $(\mathrm{A}=-0.515)$ and certain symmetry for $\bar{M}$ N6_ID $(\mathrm{A}=-0.123)$ and AP_ID $(\mathrm{A}=$ $-0.196)$. This is to say that the CCT_ID base shows a concentration of frequencies towards higher values, while for MN6_ID and AP_ID this concentration is given with medium values. The greatest asymmetry difference for ID was between CCT_ID $(\mathrm{A}=-0.515)$ and MN6_ID $(\mathrm{A}=-0.123)-\Delta \mathrm{A}=0.39$. As for the IDif parameters, the three bases show positive asymmetry, where the greatest difference of asymmetry for ID (0.8) occurs between CCT_IDif and MN6_IDif. In Figures 4-6 are presented the graphs of the weather records obtained with METEONORM (Figure 4) and (Figure 5), as well as the ones generated at the CCT Mendoza station (Figure 6), sometimes noted as MN6, AP and CCT. The (x) axis represents the weeks of the year (Wk) and the (y) axis the global solar radiation incident [W/m2].

\subsection{Outside horizontal illuminance}

In this section, the annual occurrence of Eh $10,0001 x, \quad E h=10,000-100,0001 x \quad$ and

Table 2. General statistics for direct (ID) and diffuse irradiance (IDif) under ARG_MzaMN6, ARG_MzaAP and ARG_MzaCCT conditions.

\begin{tabular}{|c|c|c|c|c|c|c|}
\hline & MN6_ID & MN6_IDif & AP_ID & AP_IDif & CCT_ID & CCT_IDif \\
\hline \multicolumn{7}{|l|}{$\mathrm{N}$} \\
\hline Valid (values $>1$ ) & 3775 & 4471 & 3800 & 4469 & 3680 & 4239 \\
\hline Lost (values $=0$ ) & 4985 & 4289 & 4960 & 4291 & 5080 & 4521 \\
\hline Mean & 514.91 & 146.84 & 524.69 & 143.70 & 598.34 & 117.72 \\
\hline Standard deviation & 327.708 & 117.243 & 314.01 & 111.797 & 337.234 & 86.928 \\
\hline Asymmetry & -0.123 & 1.034 & -0.196 & 1.051 & -0.515 & 1.879 \\
\hline Typical asymmetry error & 0.040 & 0.037 & 0.040 & 0.037 & 0.040 & 0.038 \\
\hline Kurtosis & -1.363 & 0.273 & -1.279 & 0.449 & -1.182 & 4.076 \\
\hline Typical kurtosis error & 0.080 & 0.073 & 0.079 & 0.073 & 0.081 & 0.075 \\
\hline Minimum & 2 & 2 & 2 & 2 & 2 & 11 \\
\hline Maximum & 1075 & 546 & 1073 & 529 & 1075 & 630 \\
\hline
\end{tabular}



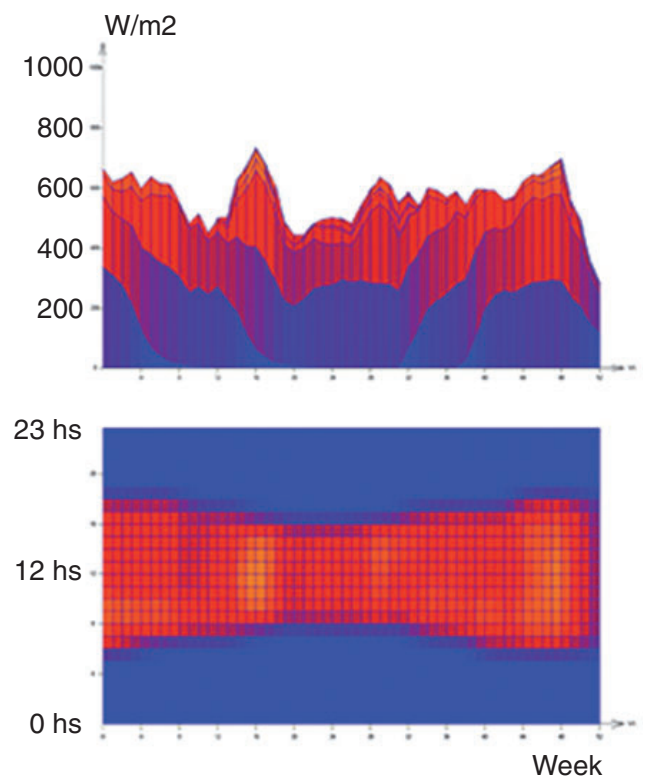

Figure 4. ARG_MzaMN6, Latitude -32.70, longitude 68.00, Time Zone 60, Site elevation $780 \mathrm{msm}$.

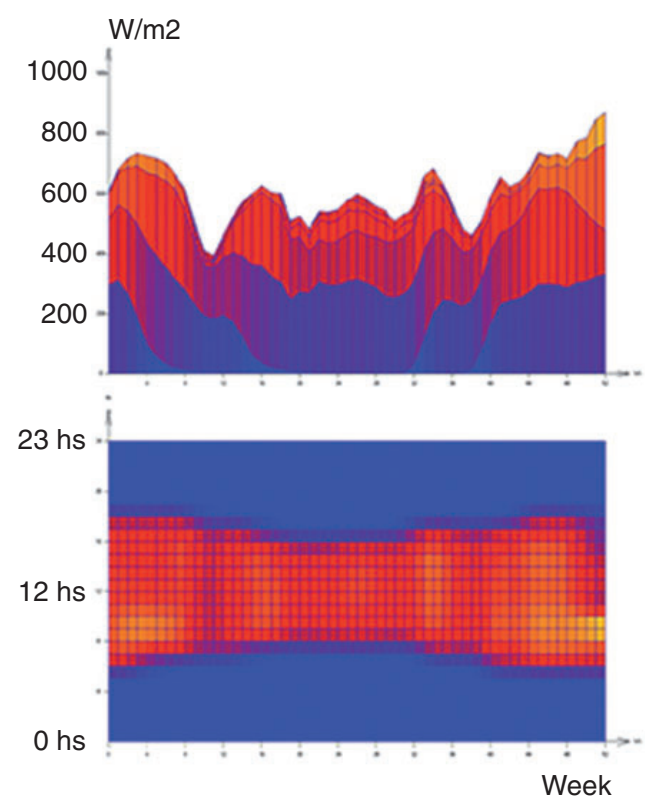

Figure 5. ARG_MzaAP, Latitude -32.83; longitude 68.78, Time Zone 60, Site elevation $704 \mathrm{msm}$.
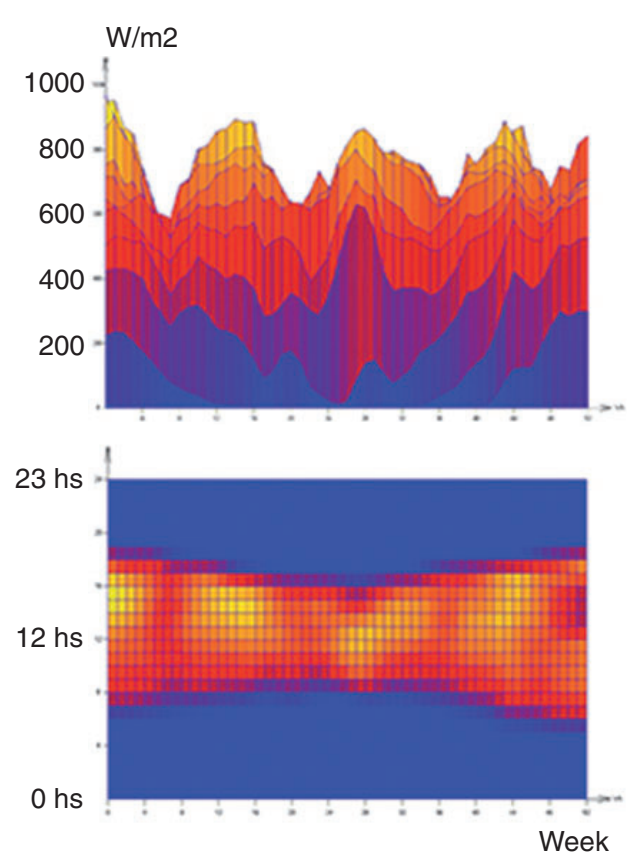

Figure 6. ARG_MzaCCT, Latitude -32.5, longitude 68.5, Time Zone 60, Site elevation $700 \mathrm{msm}$.

Eh $>100,0001 x$, obtained by simulation, under ARG_MzaMN6 and ARG_MzaCCT conditions (Table 3) are analysed.

Table 3 shows that by comparing the values of exterior horizontal illuminance under condition ARG MzaMN6 and condition ARG_MzaCCT, annual values of Eh 10,000 $100,0001 \mathrm{x}$ are overestimated by $22 \%$. However, for Eh $<10,000 \mathrm{~lx}$ and Eh $>100,0001 x$, these conditions are reversed and are underestimated by $6 \%$ and $16 \%$, respectively. When analysing the variations according to seasonal periods, it is verified that the annual overstatement found within the range of 10,000-100,000 lx occurs differentially in the summer $(19 \%)$, spring-fall $(33 \%)$ and winter $(6 \%)$ periods. Likewise, the Eh $<10,0001 \mathrm{x}$ and $\mathrm{Eh}>100,000 \mathrm{~lx}$ categories maintain an annual underestimation in all periods analysed, steeper in the summer $(13 \%)$ and spring-fall $(24 \%)$ periods. 
Table 3. Annual percentage of occurrence of illuminance in the different ranges analysed: Eh $<10000 \mathrm{~lx}$, Eh $10000-$ $100000 \mathrm{~lx}, \mathrm{Eh}>100000 \mathrm{~lx}(\%)$.

\begin{tabular}{|c|c|c|c|c|c|c|c|c|}
\hline & \multicolumn{4}{|c|}{ MN6 (satellite data) } & \multicolumn{4}{|c|}{ CCT (land-based station data) } \\
\hline & \multirow[t]{2}{*}{ Annual } & \multicolumn{3}{|c|}{ Seasonal periods } & \multirow[t]{2}{*}{ Annual } & \multicolumn{3}{|c|}{ Seasonal periods } \\
\hline & & (1) & (2) & (3) & & (1) & (2) & (3) \\
\hline$E h_{<10000 \mathrm{Ix}}(\%)$ & 12 & 1 & 10 & 28 & 18 & 7 & 19 & 29 \\
\hline $\mathrm{Eh}_{10000-100000 \mathrm{Ix}}(\%)$ & 81 & 79 & 87 & 72 & 59 & 60 & 54 & 66 \\
\hline$E h_{>100000 \mathrm{Ix}}(\%)$ & 7 & 20 & 3 & 0 & 23 & 33 & 27 & 5 \\
\hline
\end{tabular}

Table 4. aUDI and SDA 500 lux, 50\% under MN6 and CCT conditions - classroom A2.

\begin{tabular}{|c|c|c|c|c|c|c|c|c|}
\hline & \multicolumn{8}{|c|}{ Classroom A2 } \\
\hline & \multicolumn{4}{|c|}{ MN6 (satellite data) } & \multicolumn{4}{|c|}{ ССТ (land-based station data) } \\
\hline & \multirow[t]{2}{*}{ Annual } & \multicolumn{3}{|c|}{ Seasonal periods } & \multirow[t]{2}{*}{ Annual } & \multicolumn{3}{|c|}{ Seasonal periods } \\
\hline & & (1) & $(2)$ & (3) & & (1) & (2) & (3) \\
\hline $\mathrm{aUDI}_{<500 \mid x}$ & 52 & 42 & 47 & 68 & 56 & 44 & 53 & 72 \\
\hline aUDI $_{500-2500 \mid x}$ & 41 & 49 & 44 & 29 & 35 & 44 & 38 & 22 \\
\hline $\mathrm{aUDI}_{>2500 \mathrm{Ix}}$ & 7 & 10 & 9 & 3 & 9 & 12 & 9 & 6 \\
\hline aUDI & 44 & 58 & 58 & 17 & 25 & 42 & 33 & 0 \\
\hline $\mathrm{sDA}_{500(50 \%)}$ & 53 & 67 & 58 & 33 & 45 & 67 & 50 & 17 \\
\hline
\end{tabular}

aUDI: adjustable useful daylight illuminance; sDA: spatial daylight autonomy.

\section{3 aUDI and SDA}

The following section discusses the results of the dynamic daylight simulations. In more detail, this section will report the analysis of the results from spaces (A2) and (A3) in terms of aUDI (aUDI $<5001 \mathrm{x}, \quad \mathrm{aUDI}_{500-2500 \mathrm{~lx}}$, $\left.\mathrm{aUDI}_{>2500 \mathrm{~lx}}\right)$ and daylit area (aUDI ${ }_{500-2500 \text {, }}$ $50 \%, \mathrm{sDA}_{5001 \mathrm{x}, 50 \%}$ ) values. Dynamic daylight metric results are summarized in Tables 4 and 5.

\subsubsection{Classroom A2 with EW window orientation}

Results indicate that annual values of aUDI $_{500-2500} \mathrm{~lx}$ are overestimated by $6 \%$ under MN6 sky condition. This behaviour is also observed in the summer (5\%), spring-fall $(6 \%)$ and winter $(7 \%)$ periods. Values located below and those above of the useful range are underestimated by $4 \%\left(\mathrm{aUDI}_{<5001 \mathrm{x}}\right)$ and $2 \%$ $\left(\mathrm{aUDI}_{>2500 \mathrm{~lx}}\right)$ for the MN6 condition. Seasonal differences of aUDI ${ }_{500-2500} 1 \mathrm{x}$ do not exceed $7 \%$. The results of the aUDI metrics under different sky conditions are displayed in Table 4. According to the analysed daylit area with aUDI $500-2500 \mathrm{kx}$, $50 \%$, an annual overestimation of $19 \%$ in MN6 conditions is observed with the main difference in the spring-fall period $(25 \%)$. The metric $\mathrm{sDA}_{500} 1 \mathrm{x}, 50 \%$ also presents an overestimation of $8 \%$ under condition MN6.

\subsubsection{Classroom A3 with NS window orientation}

Under different sky conditions (satellite data and land-based station data), this space presents annual values of aUDI $500-25001 \mathrm{k}$ with an overestimation of $13 \%$ for MN6 with respect to the CCT sky condition.

Lighting Res. Technol. 2015; 0: 1-13 
Table 5. aUDI and sDA 500 lux, 50\% under MN6 and CCT conditions - Classroom A3.

\begin{tabular}{|c|c|c|c|c|c|c|c|c|}
\hline & \multicolumn{8}{|c|}{ Classroom A3 } \\
\hline & \multicolumn{4}{|c|}{ MN6 (satellite data) } & \multicolumn{4}{|c|}{ СCT (land-based station data) } \\
\hline & \multirow[t]{2}{*}{ Annual } & \multicolumn{3}{|c|}{ Seasonal periods } & \multirow[t]{2}{*}{ Annual } & \multicolumn{3}{|c|}{ Seasonal periods } \\
\hline & & (1) & (2) & (3) & & (1) & (2) & (3) \\
\hline $\mathrm{aUDI}_{<500 \mathrm{Ix}}$ & 37 & 40 & 33 & 37 & 50 & 42 & 40 & 68 \\
\hline $\mathrm{aUDI}_{500-2500 \mathrm{~lx}}$ & 60 & 60 & 65 & 56 & 47 & 58 & 54 & 29 \\
\hline $\mathrm{aUDI}_{>2500 \mathrm{Ix}}$ & 3 & 0 & 2 & 7 & 3 & 0 & 6 & 3 \\
\hline aUDI $I_{500-2500(50 \%)}$ & 81 & 67 & 92 & 83 & 47 & 67 & 67 & 8 \\
\hline $\mathrm{sDA}_{500(50 \%)}$ & 84 & 67 & 92 & 92 & 53 & 67 & 83 & 8 \\
\hline
\end{tabular}

aUDI: adjustable useful daylight illuminance; sDA: spatial daylight autonomy.

This behaviour is constant in the summer $(2 \%)$, spring-fall $(11 \%)$ and winter $(27 \%)$ period. Thus, the sky conditions created using MN6 results in annual and seasonal percentages of daylight availability in the usable range (aUDI $500-2500 \mathrm{~lx})$ are higher than those obtained by the CCT data. In Table 5 , the annual impacts of sky conditions on illuminance values located above and below the useful range (aUDI ${ }_{500-25001 \mathrm{l}}$ ) are analysed. Regarding aUDI $<500 \mathrm{~lx}$, it shows an underestimation of $13 \%$ under the MN6 condition. For higher annual illuminance values (aUDI $2500 \mathrm{~lx}$ ), no differences were found. However, in a more detailed analysis of illuminance seasons - values below and above of aUDI 500-2500 lx, display important differences according to the used weather file type. The main difference $(27 \%)$ of aUDI $500-2500 \mathrm{~lx}$ was found for the winter period. The results of the aUDI metrics are displayed in Table 5. For classroom A3, with NS surfaces of glass, a $34 \%$ annual overestimation of aUDI $_{500-25001 x, 50 \%}$ and a $31 \%$ annual overestimation of $\mathrm{sDA}_{500 \mathrm{~lx}}, 50 \%$, can be observed under MN6 conditions when compared to the CCT conditions. Main differences are seen in the winter period. According to the seasonal analysis, the main difference is observed during the winter, with an overestimation of
$84 \%$ of the daylit area under the MN6 condition.

\section{Discussion}

Global surface solar irradiation is necessary information for the design and evaluation of environments employing daylight. The usefulness of local weather files lies in the correct calibration and precision of dynamic daylighting simulations. While the use of satellite weather files is a possibility in regions without terrestrial stations, it is necessary to know and consider their influence on dynamic simulations. This is of fundamental importance when choosing an adequate daylighting strategy during the design phase.

This paper presents comparisons between the results obtained from simulations using different weather data files of the available exterior global horizontal illuminance and indoor horizontal illuminance in two classrooms located in Mendoza City (Argentina). First, the data offered by different climate files - satellite data (ARG_MzaMN6 and ARG_MzaAP) and land-based station data $\left(\mathrm{ARG}{ }_{-}\right.$MzaCCT) - are compared. Results showe $\bar{d}$ variations in ID and IDif calculated irradiance values. Satellite data present an underestimation of the ID $(\triangle X=73.65 \mathrm{~W} /$ 
$\mathrm{m}^{2}$ ) and an overestimation of the IDif $\left(\triangle \mathrm{X}=29.12 \mathrm{~W} / \mathrm{m}^{2}\right)$ while maintaining a similar dispersion for both cases. Subsequently, sky conditions were generated from climate files: ARG_MzaMN6 and ARG_MzaCCT in order to quantify their effects on dynamic daylighting simulation results. A comparison between the outside global horizontal illuminance $\left(E_{10} 000-1000001 x\right)$ demonstrated that the use of the two selected weather files causes differences in the simulation results of up to $24 \%$ (annual). Furthermore, an overestimation of $22 \%$ for the exterior horizontal illuminance $\left(\mathrm{Eh}_{10} \quad 000-100000 \mathrm{~lx}\right)$ was detected under ARG_MzaMN6 sky condition, and an underestimation was detected for Eh $<10000 \mathrm{~lx}$ and $\mathrm{Eh}>100000 \mathrm{~lx}$, of $6 \%$ and $16 \%$, respectively. These results are consistent with previous research developed in the region, ${ }^{13}$ where overestimations in satellite values regarding terrestrial values were found.

The present study also demonstrates that there are variations in daylight simulation results obtained with different weather files. In the classrooms analysed the most important variations were found for the aUDI and sDA indicators in the NS window orientation (A3) space. For the aUDI ${ }_{500-25001 x}$, an annual underestimation of $13 \%$ and seasonal underestimation $27 \%$ (winter period) were found under condition MN6. An annual overestimation of $31 \%$ and a seasonal (winter period) overestimation of $84 \%$ were found in relation to the daylit areas $\left(\mathrm{sDA}_{500 \mathrm{~lx}, 50 \%}\right)$. From these results, the direct influence of statistical variations found between the analysed bases is evidenced in daylight dynamic simulation results. It is evident that these differences influence the creation of the sky model obtained from the predictive analysis of daylight. Importantly, this paper initiates a series of new studies that delve deeper into this subject. These results influence the prediction of minimum and maximum illuminance values and, more importantly, the selection and design of solar control strategies so as to avoid thermal and visual discomfort. This may lead to window blocking, thus generating shady spaces and the subsequent requirement of electricity for daytime lighting. ${ }^{28}$

\section{Conclusions}

The use of dynamic metrics offers a more representative and sensitive context for studying daylight conditions. However, new challenges arise based on the correct manipulation and loading of required inputs (geometry, grid, materials and weather record). Although high accuracy is currently provided by computer-assisted designed (CAD) environments - geometry and grid - and bidirectional scattering distribution functions (BSDF) materials, such precision is not found in the weather data input. Therefore, an objective of this work is to contribute to the comparative analysis of weather data files - satellite and land-based. Results show that weather files influence daylight predictive simulation outcomes and that there are differences in daylight simulations according to the weather data file used. Even though such differences are usually not significant, in some cases, they are very relevant. Therefore, a further step in this research project is the evaluation of such differences on energy consumption and the prediction of visual comfort.

\section{Declaration of conflicting interests}

The author(s) declared no potential conflicts of interest with respect to the research, authorship, and/or publication of this article.

\section{Funding}

The author(s) disclosed receipt of the following financial support for the research, authorship, and/or publication of this article: This 
research was supported by National Scientific and Technical Research Council (CONICET - Argentina).

\section{References}

1 Li DHW, Lam JC, Lau CS, Huan TW. Lighting and energy performance of solar film coating in air-conditioned cellular offices. Renewable Energy 2004; 29: 921-937.

2 Partonen T, Lonnqvist J. Bright light improves vitality and alleviates distress in healthy people. Journal of Affective Disorders 2000; 57: 55-61.

3 Heschong L. Daylighting and human performance. ASHRAE Journal 2002; 446: 65-67.

4 Boyce P, Hunter C, Howlett O. The Benefits of Daylight through Windows. Troy, NY:

Lighting Research Center, 2003.

5 Stevens R, Blask D, Brainard G, Hansen J, Lockley S, Provencio I, Reinlib L. Meeting report: the role of environmental lighting and circadian disruption in cancer and other diseases. Environmental Health Perspectives 2007; 115: 1357-1362.

6 Duffy J, Czeisler C. Effect of light on human circadian physiology. Sleep Medicine Clinics 2009; 4: 165-177.

7 Jarvis D, Donn M. Comparison of computer and model simulations of a daylit interior with reality: Proceedings of the Fifth International IBPSA Conference/Building Simulation 97, Prague, Sept 8-10: 1997.

8 Ward LG, Shakespeare R. Rendering with Radiance: The Art and Science of Lighting Visualization. San Francisco: Morgan Kaufmann Publishers, 1998.

9 Perez R, Seals R, Michalsky J. All-weather model for sky luminance distribution Preliminary configuration and validation. Solar Energy 1993; 50: 235-245.

10 Reinhart C, Mardaljevic J, Rogers Z. Dynamic daylight performance metrics for sustainable building design. Leukos 2006; 3 : 7-31.

11 Mardaljevic J. Daylight simulation: Validation, sky models and daylight coefficients. $\mathrm{PhD}$ thesis. Leicester, UK: de Montfort University, 2000 .
12 Perez R, Ineichen P, Seals R, Michalsky J, Stewart R. Modeling daylight availability and irradiance components from direct and global irradiance. Solar Energy 1990; 44: 271-289.

13 Raichijk C. Comparación de valores satelitales de irradiación solar global con datos de tierra en la República Argentina. Avances en Energías Renovables y Medio Ambiente 2009; 13: 11.07-11.10.

14 Bellia L, Pedace A, Fragliasso F. Dynamic daylight simulations: Impact of weather file's choice. Solar Energy 2015; 117: 224-235.

15 Iversen A, Svendsen S, Nielsen TR. The effect of different weather data sets and their resolution on climate-based daylight modelling. Lighting Research and Technology 2012; 45: 305-316.

16 Monteoliva JM, Villalba A, Pattini A. Impacto de la utilización de bases climáticas regionales en la simulación de alta precisión de iluminación natural. Energías Renovables y Medio Ambiente 2013; 31: 37-44.

17 Tregenza PR, Waters IM. Daylight coefficients. Lighting Research and Technology 1983; 15: 65-71.

18 Reinhart C, Walkenhorst O. Dynamic RADIANCE-based daylight simulations for a full-scale test office with outer venetian blinds. Energy and Buildings 2001; 33: 683-697.

19 Monteoliva, JM, Pattini, A. SeasonSIM: Herramienta de pos-procesamiento estadístico estacional para el análisis del comportamiento de la iluminación natural anual de un espacio. Versión 1.0. Mendoza: Grupo de Habiente Humano y Vivienda. (Registro CONICET, Exp. 5159481), 2014.

20 Córica L. Comportamiento de la Luz Natural en Entornos Urbanos Representativos del Modelo Oasis en Regiones Aridas. Caso de estudio: Ciudad de Mendoza. Tesis Doctoral. Tucumán, Argentina: Universidad Nacional de Tucumán, 2009 . .

21 Villalba A, Monteoliva JM, Pattini A. Filtros de control solar sobre superficies vidriadas.

Evaluación lumínica mediante métricas dinámicas y preferencia de usuarios. Energías

Renovables y Medio Ambiente 2011; 28: 27-36.

22 Commission Internationale de l'Eclariage. Guide to Recommended Practice of Daylight 
Measurement. Technical Report CIE 108-1994, Vienna: CIE, 1994.

23 Rogers Z. Daylighting Metric Development Using Daylight Autonomy Calculations in the Sensor Placement Optimization Tool. Boulder, CO: Architectural Energy Corporation, 2006.

24 Nabil A, Mardaljevic J. Useful daylight illuminance: A new paradigm to access daylight in buildings. Lighting Research and Technology 2005; 37: 41-59.

25 Nabil A, Mardaljevic J. Useful daylight illuminances: A replacement for daylight factors. Energy and Buildings 2006; 38: 905-913.
26 Monteoliva JM, Pattini A. Metodologías para el análisis dinámico del factor iluminación de alta precisión en espacios educativos: Memorias de XI Jornadas Argentinas de Luminotecnia, Tucumán, 3-4 October 2013.

27 Illuminating Engineering Society of North America, IES LM-83-12. IES Spatial Daylight Autonomy (sDA) and Annual Sunlight Exposure (ASE). New York: IESNA, 2012.

28 Pattini A. La Luz Natural en las Escuelas: Aprovechamiento y Control de la Luz Solar en Aulas. Buenos Aires: Dunken, 2009. 